\title{
"Extreme Observations and
}

\section{Diversification in Latin}

\section{American Emerging Equity Markets"}

\author{
R A U L S S M E L \\ ( University of Houston)
}

LOCAL

Fundação Getulio Vargas

Praia de Botafogo, 190 - $10^{\circ}$ andar - Auditório

\author{
DATA \\ 06/08/98 ( $5^{\mathbf{a}}$ feira) \\ HORÁRIO \\ 16:00h
}

Coordenação: Prof. Pedro Cavalcanti Gomes Ferreira Email: ferreira@fgv.br - $\mathbf{P}(021)$ 536-9250 


\title{
EXTREME OBSERVATIONS AND DIVERSIFICATION IN LATIN AMERICAN EMERGING EQUITY MARKETS
}

\author{
Raul Susmel ${ }^{*}$ \\ University of Houston \\ Department of Finance \\ College of Business Administration \\ Houston, TX 77204-6282 \\ (713) $743-4763$ \\ FAX: (713) 743-4789 \\ e-mail: rsusmel@menudo.uh.edu
}

March 1998

\begin{abstract}
In this paper, we focus on the tails of the unconditional distribution of Latin American emerging markets stock returns. We explore their implications for portfolio diversification according to the safety first principle, first proposed by Roy (1952). We find that the Latin American emerging markets have significantly fatter tails than industrial markets, especially, the lower tail of the distribution. We consider the implication of the safety first principle for a U.S. investor who creates a diversified portfolio using Latin American stock markets. We find that a U.S. investor gains by adding Latin American equity markets to her purely domestic portfolio. For different parameter specifications. we find a more realistic asset allocation than the one suggested by the literature based on the traditional mean-variance framework.
\end{abstract}

JEL: C53, G15

* I thank Rich Pettit and Ramon Rabinovitch for his useful comments. 


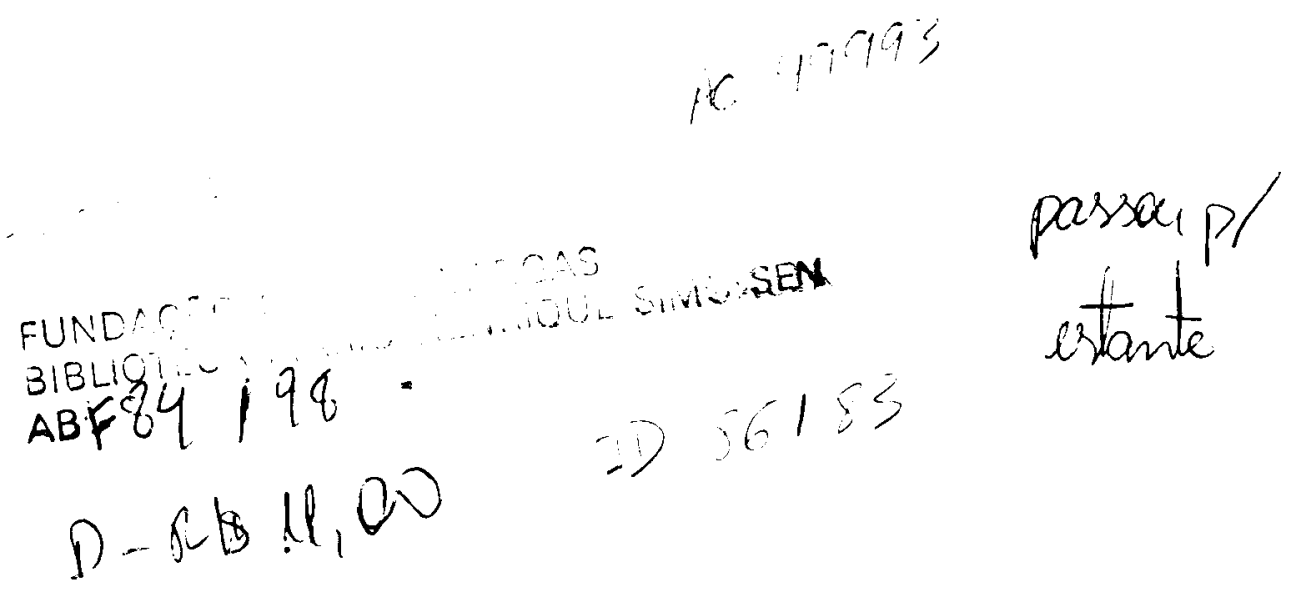


Title: Extreme Observations and Diversification in Emerging Equity Markets

\begin{abstract}
In this paper, we focus on the tails of the unconditional distribution of Latin American emerging markets stock returns. We explore their implications for portfolio diversitication according to the safety first principle, first proposed by Roy (1952). We find that the Latin American emerging markets have significantly fatter tails than industrial markets. especially, the lower tail of the distribution. We consider the implication of the safety first principle for a U.S. investor who creates a diversified portfolio using Latin American stock markets. We find that a U.S. investor gains by adding Latin American equity markets to her purely domestic portfolio. For different parameter specifications, we find a more realistic asset allocation than the one suggested by the literature based on the traditional mean-variance framework.
\end{abstract}




\section{I.- INTRODUCTION}

The well documented high average stock returns and their low correlations with industrial markets seem to make emerging equity markets an attractive choice for diversifying portfolios. De Santis (1993) finds that adding assets from emerging markets to a benchmark portfolio consisting of U.S. assets creates portfolios with a considerable improved reward-to-risk performance. Harvey (1995a) finds that adding equity investments in emerging markets to a portfolio of industrial equity markets significantly shifts the mean-variance efficient frontier to the left. Within the context of a traditional mean-variance context, Harvey (1994) provides a detailed analysis of conditional and unconditional asset allocation that includes emerging markets. He finds that the optimal unconstrained weights for emerging markets increase over time from $40 \%$ in 1980 to almost $90 \%$ in 1992. Using the Latin American markets used in these papers, the optimal unconstrained weights for the Latin American markets is close to $50 \%$. The above results seem to contrast with the also well documented "home bias," see French and Poterba (1991) and Tesar and Werner (1994, 1995). In particular, Tesar and Werner (1995) study U.S. equity flows to emerging stock markets and find that the U.S. portfolio remains strongly biased toward domestic equities. For example, Chuhan (1992) tinds that investment in emerging markets was roughly 2 to 3.5 percent of the international portfolio held by U.S. pension funds from 1988 to 1991 .

In this paper, we explore the implications of the safety first criterion in an international asset allocation context. Roy (1952) introduced the safety first criterion, which was further developed by Arzac and Bawa (1977). Under the safety first criterion, an investor minimizes the chance of a very large negative return, a return that, if realized, would reduce the investor's portfolio value below some threshold level. A safety first investor might be worried about a one-time large event that might drive her or her firm out of business. The safety first rule might be more appropriate for investors investing in emerging markets than in well established markets because emerging markets equity distributions 
are greatly influenced by extreme returns.' As shown in this paper. one of the differences between emerging and industrial markets is the hehavior of extreme returns. These observed extreme returns produce a fatter tailed empirical distribution for emerging markets stock returns than for the industrial markets.

Fat tails for stock returns in industrial markets have been extensively studied. Mandelbrot (1963) and Fama (1965) point out that the distribution of stock returns has fat tails relative to the normal distribution. Mandelbrot (1963) proposes a non-normal stable distribution for stock returns, in which case the variance of the distribution does not exist. Blattberg and Gonedes (1974) and, later, Bollerslev (1987), in an ARCH context, propose the Student-t distribution for stock returns, which has the appeal of a finite variance with fat tails. Jansen and de Vries (1991) and Loretan and Phillips (1994) use extreme value theory to analyze stock return in the U.S. Their results indicate the existence of second moments and possibly third and fourth moments, but not much more than the fourth moment. Jansen, Koedijk and de Vries (1996), JKV thereafter, use extreme value theory to operationalize the safety first rule in portfolio selection. They show that using extreme value theory allows calculations of the probability of extreme events, even for an event for which there is no in-sample observation. This approach is very useful for decision makers that worry about the possible occurrence of an extreme event.

In this paper, we focus on Latin American emerging markets. These markets are of particular interest to U.S. investors. Among emerging markets, they have been the largest recipients of U.S. net purchases of foreign equity from 1978 till 1991. see Tesar and Werner (1995). De Santis (1993) finds that the Latin American markets are associated with the largest gain in portfolio performance to a U.S.

${ }^{1}$ Harvey (1995a, 1995b) and Claessens et al. (1995) document that emerging markets returns significantly depart from normality. This departure from normality is greatly intluenced by the behavior of extreme returns. 
investor who wants to diversify a purely domestic portfolio. In addition, these markets have undergone substantial changes in financial regulations and macroeconomic policies. We find that emerging markets have fatter tails than industrial markets. The tail estimates suggest that the distribution of Latin American emerging markets might not have second moments. We also tind that a U.S. investor gains by adding Latin American equity markets to her purely domestic portfolio. For different parameter specifications, however, we find a Latin American portfolio weight of $15 \%$, which is a more realistic asset allocation than the one suggested in the literature hased on the traditional mean-variance framework.

This paper is organized as follows. Section II briefly introduces the safety first principle and the JKV approach to operationalize it. Section III describes the data and performs a preliminary analysis of the series. Section IV summarizes the results. Section V concludes the paper.

\section{SAFETY FIRST AND EXTREME VALUE THEORY}

\section{II.A Safety First ${ }^{2}$}

Suppose an investor's initial wealth and initial value of asset $\mathrm{j}$ are $\mathrm{W}_{\mathrm{o}}$ and $\mathrm{V}_{\mathrm{o}, \mathrm{j}}$, respectively. This investor can invest in the risky assets with weights $\omega . j$ 's or borrow and lend an amount $b$ at the free-risk rate $\mathrm{r}$ ( $\mathrm{b}>0$ represents borrowing). A safety first investor specifies a disaster level of wealth, $s$, and the maximal acceptable probability of this disaster, $\delta$. Let $W_{1, j}$ he the random final value of asset $j$ and let $\mu$ be the expected return of the portfolio. i.e. $\mu=E(R)$. Arzac and Bawa (1977) study the implications of the following lexicographic form of the safety first principle:

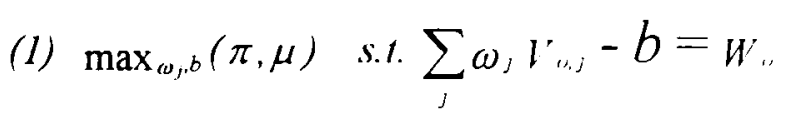

${ }^{2}$ This section is based on Arzac and Bawa (1977). 
where

$$
\begin{aligned}
& \pi=1, \text { if } \mathrm{P}=\operatorname{Prob}\left(\Sigma_{j} \omega_{i} \mathrm{~W}_{1, j}-\mathrm{br} \leq \mathrm{s}\right) \leq \delta . \\
& \pi=1-\mathrm{P}, \quad \text { otherwise. }
\end{aligned}
$$

The safety first condition can be written as

$$
\text { (2) } \operatorname{Prob}\left(\mathrm{R} \leq \mathrm{q}_{\delta}(\mathrm{R})\right) \leq \delta \text {, }
$$

where $R$ is the return of the investor's portfolio, and $q_{i}=\left(r+\left(s-W_{0} r\right) /\left(W_{0}+b\right)\right.$. The return of the portfolio can only be below the quantile $q_{i}$ with probability $\delta$. The safety first principle is violated whenever

$$
\text { (3) } q_{\delta}(R)<r+\frac{s-W_{o} r}{W_{o}+b} \text {. }
$$

Note that a safety first investor will exhibit risk aversion if the critical wealth level $s$ is smaller than his/her secure final wealth $\mathrm{W}_{\mathrm{o}} \mathrm{r}$. Arzac and Bawa (1977) show that a risk averse safety first investor can solve the optimization problem in two stages. First, the investor maximizes the ratio of the risk premium to the return opportunity loss that she can incur with probability $\delta$,

$$
\text { (4) } \max _{\omega} \frac{E(R)-r}{r-q_{\delta}(R)}
$$

and determine the optimal weights, the $\omega_{i}$ 's. In the second stage, the investor determines the amount to be borrowed from the budget constraint and the scale of the risky part of his/her portfolio from

(5) $W+b=\frac{s-W_{o} r}{q_{i}(R)-r}$.

In order to derive testable implications for the safety first theory, it is necessary to specify the $\delta^{-}$ fractile of the portfolio in terms of estimable characteristics of the risky assets. Roy (1952) and Arzac and Bawa (1977) proposed using the Tchehychev inequality to approximate the tail of the risky 
portfolio distribution from above. That is.

(6) $P\left[(R-E(R))^{2} \geq(E(R)-q)^{2}\right] \leq \frac{\sigma^{2}}{|E(R)-q|^{2}}$.

for $\mathrm{E}(\mathrm{R})>\mathrm{q}$. As shown by $\mathrm{JKV}$, the Tchebychev bound may be a poor approximation to the exact bound. They improve the bound by using extreme value theory.

\section{II.BExtreme value theory ${ }^{3}$}

Consider a stationary sequence of $X_{1}, X_{2}, \ldots X_{n}$ of i.i.d random variables with distribution function $F($.$) . We want to find the probability that M_{n}$, the maximum of the first $n$ random variables, is below a certain value $x\left(M_{n}\right.$ could be multiplied by -1 if one is interested in the minimum). We denote this probability by $P\left(M_{n}<x\right)=F^{n}(x)$. The distribution function $F^{\prime \prime}(x)$, when suitably normalized and for large $n$, converges to a limiting distribution $G(x)$. where $G(x)$ is one of three asymptotic distributions, see Leadbetter, Lindgren and Rootzen (1983). Since returns on financial assets are fat tailed, Koedijk et al. (1990) and JKV consider the limiting distribution of $\mathrm{G}(\mathrm{x})$ which is characterized by a lack of some higher moments:

$$
\begin{aligned}
(7) \mathrm{G}(\mathrm{x}) & =0, & & \text { if } \mathrm{x} \leq 0 . \\
& =\exp (-\mathrm{x})^{-1 / \gamma}=\exp (-\mathrm{x})^{-\alpha}, & & \text { if } \mathrm{x}>0 .
\end{aligned}
$$

where $\gamma=1 / \alpha>0$ and $\alpha$ is the tail index. Leadhetter. Lindgren and Rootzen (1983) show that when the dependence among the $X_{i}$ 's is not too strong. this limiting distrihution is valid. The Student-t.with finite degrees of freedom, the stable distrihution. and the ARCH process are included in the above $\mathrm{G}(\mathrm{x})$ distribution. For the Student-t distribution. $\alpha$ is the degrees of freedom. The symmetric stable distribution requires $\alpha$ to be lower than two. The tail index $\alpha$ can be estimated and indicates the

\footnotetext{
${ }^{3}$ This section is based on JKV. Section III.
} 
number of moments that exist.

To estimate $\alpha$ we use Hill's (1975) moment estimator. We first obtain the order statistics $X_{(n)}, X_{(11}$. ${ }_{11}, \ldots, X_{(1)}$ from our sample, where $X_{(n)}>X_{(n-1)}>\ldots>X_{(1)}$, etc. Then, the Hill estimator is given by:

(8) $\hat{\gamma}=\frac{1}{m} \sum_{i=1}^{1=m} \ln \left(X_{n+1-1}\right)-\ln \left(X_{n-m}\right)$,

where $m$ is the number of upper order statistics included. The Hill estimator can be applied to either tail of a distribution by calculating order statistics from the opposite tail and multiplying the data by -1 . We can also combine the tail observations (by taking absolute values) to estimate a common $\alpha$. Goldie and Smith (1987) show that $(1 /-1 / \alpha) \mathrm{m}^{1 / 2}$ is asymptotically normal $\mathrm{N}\left(0, \gamma^{2}\right)$ if $\mathrm{m}$ increases suitable as $\mathrm{n}$ tends to infinity. The asymptotic normality of 1/_ makes testing hypotheses about the tails of the distribution very easy.

One critical aspect of the Hill estimator is the choice of $\mathrm{m}$. We use a bootstrap procedure proposed by Hall (1990), which is also used by JKV. After calculating $\alpha$ we estimate the quantiles $q_{p}$ using the following formula:

(9) $q_{p}=X_{(n-m)}(m / p n \dot{y}$.

This formula estimates the quantiles $q_{p}$ that will only be exceeded with probability $p$.

Tail estimates using extreme value theory have been estimated for exchange rates by Hols and de Vries (1991) and Koedijk et al. (1990), and for stock returns by Jansen and de Vries (1991), Longin (1993) and JKV.

III.- DATA

Data of weekly returns of stock indexes from six industrial and four emerging Latin American markets are obtained from Morgan Stanley Capital International (MSCl). The sample covers the period 
from the last week of August 1989 to the third week of April 1996. We take 1989 as our starting date because prior to 1989 equity markets in Latin America were almost inaccessible for direct investments by foreign investors. They were accessible primarily through country funds. The return on each market is computed based on a value-weighted portfolio of securities that trade in that market. Since Latin American countries have experienced high inflation and high inflation volatility, we use returns expressed in U.S. dollars. ${ }^{4}$ All indexes are constructed so as not to double count those stocks multiplelisted on foreign stock exchanges. Stocks are selected for inclusion on the basis of liquidity and market value.

Table 1, Panel A shows univariate statistics for the data. We note the usual high return-high standard deviation characteristic of emerging markets. We test for normality using the Jarque-Bera (1980) test, JB, which follows a chi-squared distribution with two degrees of freedom. Although for both series normality is rejected by the JB, in emerging markets the rejection is stronger. ${ }^{5}$ This stronger rejection arises mainly from higher kurtosis. Panel A also shows the first autocorrelation coefficient, RHO, and Ljung-Box (1978), LB(y), autocorrelation tests. The LB test follows a chisquared distribution with q degrees of freedom. The first order autocorrelation coefficients and the LB tests, for mean returns, for both Latin American emerging markets and industrial markets are quite similar, and, with the exception of Argentina and Mexico. there is no evidence for autocorrelation. For

${ }^{4}$ McFarland, Pettit and Sung (1982) argue that weekly exchange rates also follow a non-normal stable distribution. Therefore, since the hehavior of the fattest tail dominates the tail behavior of a sum of variables, our tail estimates might capture the tail behavior of exchanges rates instead of local stock prices. We estimated the tail estimate in local currencies and the results were very similar to the results obtained in U.S. dollars. Later, we tested if the structural reforms enacted in the Latin American countries during our sample. affected the tail estimate. These structural reforms have had a stabilizing influence on exchange rates. We could not. however. reject the null hypothesis of no change after the reforms.

${ }^{5}$ Harvey (1995b) and Claessens et al. (1995) test for normality using different tests. They reject normality for many emerging markets. 
the squared returns, however, the LB test rejects the no autocorrelation null hypothesis in all the markets with the exception of the U.K.. Australia." and Canada. Latin American emerging markets tend to show even higher squared autocorrelations. In Table I. Panel B. we analyze the impact of large positive and negative observations in our sample by leaving out of the analysis the five largest and five smallest observations. All the industrial markets. with the exception of Japan and Australia, pass the JB normality test, while among the Latin American emerging markets, only Chile passes the JB normality test. The source of non-normalities in Argentina, Brazil. and Mexico does not seem to be driven solely by a few extreme observations.

Table 2 focuses on the extreme observations in our sample. Four our purposes, extreme observations are defined as observations which are outside of two standard deviations. Under normality, the expected total number should be around 17. Table 2 shows that the Latin American emerging markets tend to have a lower total number of extreme observations than the industrial markets, although they are not statistically different. For portfolio managers, it would be useful to know how clustered are these extreme observations. For example, a interesting question for portfolio managers is: once an extreme observation has happened, is the probability of observing another extreme observation higher? Table 2 also addresses this issue. Table 2 shows the number of single extreme observations, where a single extreme observation is defined as an extreme observation not followed or preceded by another extreme observation in four weeks. Again, with the exception of Germany, this number is smaller for the emerging markets than for the industrial markets. This result shows that the Latin American emerging markets tend to have the extreme observations more clustered than the industrial markets. For example, in Argentina out of eighteen extreme observations only three are single extreme observations. In contrast. in the U.K.. eleven extreme observations out of eighteen

\footnotetext{
${ }^{6}$ The first U.K. and second Austrailian squared autocorrelations are significant.
} 
are single extreme observations. Finally. the last eight columns of Tahle 2 show the two largest returns, the $95 \%$ percentile, the $90 \%$ percentile. the two smallest returns. the $5 \%$ percentile, and the $.10 \%$ percentile from each series. We find that. in absolute value. the two smallest returns tend to be larger than the two largest returns. This hehavior of the extreme observations seems to reverse faster in emerging markets than in industrial markets, as the percentile in Table 2 show. We also find that the two largest returns tend to be closer than the two smallest returns. Of particular relevance to investors is the behavior of large negative returns. In the Latin American emerging markets, we find that the second smallest return is at least $40 \%$ larger than the minimum return. In industrial markets, however, the second smallest return is on average $14 \%$ larger than the minimum return. We conclude that one of the main differences between Latin American emerging markets and industrial markets is given by the behavior of the returns on the tails of the distribution. especially on the lower tail.

Table 3 shows the correlation matrix for returns and squared returns. Panel A, shows the typical low correlation of stock returns in emerging markets and industrial markets. The regional correlations are on average larger than the correlations with developed markets. These low correlations are usually interpreted as an indication of potential benefit for international portfolio diversification. With few exceptions, Panel B, shows consistently lower correlations for squared returns. Engle and Susmel (1993) show that higher correlations for the squared returns than correlations for the level returns might be indicating the existence of common time-varying components in the variance. From that perspective, the results in Panel B show no evidence of common time-varying volatility in Latin American emerging markets or in the industrial markets.

\section{TAIL ESTIMATES AND THEIR IMPLICATIONS TO INVESTORS}

IV.A Tail estimates

Table 4 reports our estimates of the tail index of the returns' distribution. The upper tail, $\alpha_{+}$, the 
lower tail, $\alpha_{-}$, and the common tail. $\alpha$. are reported in the first. second and third columns, respectively. Below each point estimate, we report standard errors and the number of order statistics used to estimate the tail index, $\mathrm{m}$.

The lower tail tends to be fatter (smaller) than the upper tail. This is especially true for all Latin American emerging markets. With the exception of Mexico. the equality of both tails, however, cannot be rejected. More important, both tails tend to be fatter for the Latin American emerging markets than for the industrial markets. This result is true for the lower tail and common tail. We also test for the existence of second moments. If $\alpha$ is signiticantly lower than two, the equity returns do not have second moments. The test is a one-sided test and follows a standard normal distribution under the null hypothesis. The null hypothesis is clearly rejected for industrial markets and for Brazil and Chile. It cannot be rejected for Mexico and Argentina.

We calculate exceedence levels for different probabilities. Recall that exceedence levels are returns that can only be achieved with a given probability. We use as probabilities for the exceedence levels multiples of the inverse of the sample size. $n=346$. In the last three columns of Table 4 we report these calculations. For example, focusing on Argentina, the fifth column indicates that with probability $1 / 346$ we can observe a negative return of $-46.7 \%$. That is, in the Argentinean case, there is a 1 in 346 chance that an investor will observe a weekly return of $-46.7 \%$ or less. Similarly, for Argentina, the last column indicates that there is an almost .001 chance that an investor would experience a weekly return of $-81.1 \%$ or less. From these last three columns, we observe that the exceedence levels are quite disperse from Latin American emerging markets. but they are quite concentrated for industrial markets.

We want to test the structural stability of the tail estimates for Latin American equity markets. These markets have experienced substantial deregulation and liheralization during the past six years. We test if the tail index has changed after liberalization for Argentina and Brazil, the two markets that 
we have enough observations to do a sensible estimation. For Argentina. the tail index is 2.63 before liberalization and 2.99 after liberalization. For Brazil. the tail index is 2.60 before liberalization and 2.80 after liberalization. Even though there is a mild decrease in the fatness of the tail, a formal test cannot reject the equality of the indexes before and after economic reform. These results complement previous results, using monthly data, that do not observe any significant change in volatility, see De Santis and Imrohoroglu (1995) and Bekaert and Harvey (1995). However, they seem to contradict Hargis (1994), who also uses weekly stock returns for the same Latin American markets. Hargis (1994) reports a decrease in volatility after liberalization.

\section{IV.B Safety first portfolio diversification}

In this section, we study the diversification possibilities which the Latin American emerging markets afford a U.S. safety first investor. Assume that the U.S. investor is considering investing in a Latin American portfolio. For simplicity, we use an equally weighted Latin American portfolio. In the U.S., the investor can lend or borrow at the risk-free rate. r. which we take as the weekly 90-day LIBOR. ${ }^{7}$ We construct 21 portfolios, increasing the percentage of the investment in the Latin American portfolio from $0 \%$ to $100 \%$ by increments of $5 \%$ (for brevity we do not report all the portfolios). As pointed out by JKV. the tail index, $\alpha$. is unaffected by forming these portfolios. since the fattest tail dominates the portfolio. In Table 5, however. we estimate all the tail indexes for all porttolios. As it can be seen, for portfolios composed of $25 \%$ or more of the Latin American portfolio, the lower tail estimates are dominated by the Latin American markets. i.e. the tail index is close to two. For portfolios composed of $20 \%$ or less of the Latin American portfolio, the contribution of the Latin American markets is too small to dominate the U.S. Index. and therefore, the tail of the portfolio is

\footnotetext{
${ }^{7}$ Using a value weighted portfolio of the Latin American does not significantly change the results.
} 
very similar to the U.S. tail.

In order to study the implications of the safety first principle for the U.S. investor, we need to specify the parameter values of $\delta$ and $s$. We assume that $\delta$ takes on two values: .0029 (once every 6.7 years, or a 1 in 346 chance) and .0014 (a 1 in 692 chance) ${ }^{\circ}$ We use two conservative values of $\mathrm{s}$ : $.9 \mathrm{~W}$ and $.95 \mathrm{~W}$. For both levels of $\delta$, the optimal investment in the Latin American portfolio is $15 \%$, which is a substantial reduction from the $50 \%$ reported in the introduction. ${ }^{9}$ The return on this risky portfolio is $.002239 \%$ a week. The exceedence levels for the safety first optimal risky portfolio are -.057 for $\delta=.0029$ and -.072 for $\delta=.0014$. Finally. we have to determine b, which depends on $s$. For example, for $\delta=.0029$ and $s=.95, b=-.128 \mathrm{~W}$, that is. the U.S. investor will be lending at the risk free rate $12.8 \%$ of her initial wealth. The return on the total portfolio is $(.872 \times 1.002239)+(.128 \times 1.001)=$ 1.00209. If the worst happens, the U.S. investor's final wealth is $(.872 \times .943) \mathrm{W}+(.872 \mathrm{x}$ $1.002239) \mathrm{W}=.949 \mathrm{~W}$, or 95 percent of the initial wealth as expected.

\section{CONCLUSIONS}

In this paper, we analyze Latin American emerging markets from a different perspective. We focus on the tails of the unconditional distribution of stock returns. We also explore the implications for portfolio diversification of the safety first principle. First. we find that the Latin American emerging markets have significantly fatter tails than industrial markets. This result is especially true for the lower tail of the distribution. Second, we consider a simple exercise to analyze the implication of the safety first principle for a U.S. investor who wants to diversify his/her domestic portfolio using Latin American markets. For different parameter specitications, we find that the safety first principle obtains

${ }^{x}$ We use different values for $\delta$. The results do not change substantially.

${ }^{9}$ This percentage is consitent with the caps used in several global investment funds and with the cap used in Harvey (1994). 
an optimal portfolio weight of $15 \%$ for all Latin American markets. 
TABLE 1. UNIVARIATE STATISTICS

A. Full Sample

$\begin{array}{lllllll}\text { MARKET Mean } & \text { S.D. SK } & \text { EK } & \text { JB } & \text { RHO LB(6) } & \text { LBS(6) }\end{array}$

I. Latin American Emerging Markets

$\begin{array}{llllrlll}\text { ARGEN } & .417 & 8.87 & -0.33 & 9.865590 .7^{*} & -.0516 .54^{*} & 55.38^{*} \\ \text { BRAZIL } & .287 & 8.98 & -1.29 & 8.243901 .6^{*} & .06 & 7.57 & 53.62^{*} \\ \text { CHILE } & .525 & 4.36 & -0.13 & 20.9225175 .2^{*} & -.08 & 8.27 & 87.27^{*} \\ \text { MEXICO } & .332 & 4.77 & -1.45 & 8.864635 .1^{*} & .1120 .99^{*} & 10.37\end{array}$

II. Industrial Markets

$\begin{array}{llllllllc}\text { AUSTR } & .087 & 2.28 & 0.09 & 0.43 & 11.3^{*} & -.08 & 10.51 & 10.02 \\ \text { CANADA } & .024 & 1.71 & -0.11 & 0.99 & 57.0^{*} & -.08 & 9.69 & 3.40 \\ \text { GER } & .170 & 2.51 & -0.50 & 1.81 & 203.6^{*} & -.01 & 5.51 & 63.02^{*} \\ \text { JAPAN } & -.038 & 3.53 & -0.34 & 3.25 & 613.8^{*} & .06 & 4.86 & 28.30^{*} \\ \text { U.K. } & .122 & 2.24 & -0.01 & 1.39 & 111.0^{*} & -.06 & 3.06 & 6.58 \\ \text { U.S. } & .178 & 1.62 & -0.46 & 2.15 & 277.0^{*} & -.06 & 5.08 & 37.89^{*} \\ \text { WORLD } & .097 & 1.70 & -0.45 & 2.22 & 295.0^{*} & -.02 & 3.84 & 115.64^{*}\end{array}$

B. Truncated Sample -five largest and five smallest observations dropped-

$\begin{array}{lllllllll}\text { MARKET Mean } & \text { S.D. SK } & \text { EK } & \text { JB } & \text { RHO } & \text { LB(6) } & \text { LBS(6) Max } & \text { Min }\end{array}$

I. Latin American Emerging Markets

$\begin{array}{lllrlrlllrr}\text { ARGEN } & .468 & 6.67 & 0.25 & 1.11 & 71.7^{*} & . . & . & . . & 23.58 & -19.35 \\ \text { BRAZIL } & .480 & 7.15 & -0.27 & 0.43 & 14.5^{*} & . . & . & . . & 17.82 & -22.68 \\ \text { CHILE } & .549 & 2.93 & 0.23 & 0.19 & 5.0 & . . & . & . & 9.21 & -8.20 \\ \text { MEXICO } & .447 & 3.81 & -0.29 & 0.33 & 11.0^{*} & . . & . . & . . & 9.99 & -12.14\end{array}$

II. Industrial Markets

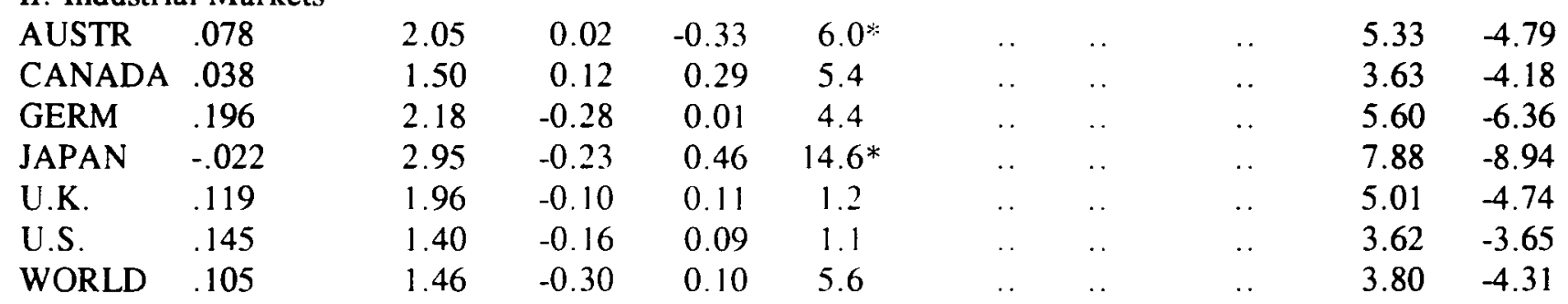

Notes:

* significant at the $5 \%$ level.

SK: Skewness coefticient.

EK: Excess kurtosis coefficient.

JB: Jarque-Bera (1980) normality test.

RHO: First order autocorrelation coefficient

LB(6): Ljung-Box statistic with 6 lags for levels.

LBS(6): Ljung-Box statistic with 6 lagss for squared series. 
TABLE 2. EXTREME OBSERVATIONS

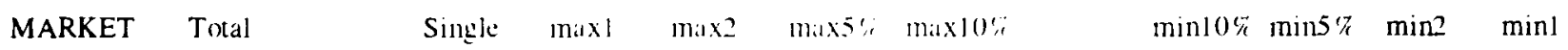

I. Latin American Emerging Markets

$\begin{array}{llrlrrrrrrr}\text {.ARGEN } & 18 & 3 & 42.84 & 41.02 & 12: 18 & 8.57 & -8.08 & -11.99 & -32.12 & -61.75 \\ \text { BRAZIL } & 15 & 4 & 31.32 & 27.52 & 13.28 & 10.11 & -9.58 & -13.47 & -38.24 & -66.81 \\ \text { CHILE } & 11 & 4 & 33.79 & 18.71 & 6.18 & 4.62 & -3.33 & -4.50 & -18.40 & -33.40 \\ \text { MEXICO } & 17 & 5 & 14.57 & 13.44 & 7.39 & 5.69 & -4.64 & -6.45 & -18.74 & -34.54\end{array}$

II. Industrial Markets

$\begin{array}{llrrrrrrrrr}\text { AUSTR } & 18 & 6 & 8.24 & 6.17 & 3.85 & 2.98 & -2.84 & -3.91 & -6.21 & -7.12 \\ \text { CANADA } & 16 & 12 & 5.58 & 4.95 & 2.95 & 2.28 & -2.07 & -2.54 & -6.16 & -6.27 \\ \text { GER } & 16 & 4 & 8.10 & 7.49 & 3.87 & 3.02 & -2.87 & -4.39 & -8.55 & -11.74 \\ \text { JAPAN } & 20 & 7 & 14.92 & 10.94 & 5.56 & 3.96 & -3.88 & -6.32 & -12.37 & -18.06 \\ \text { U.K. } & 18 & 11 & 8.62 & 8.04 & 3.83 & 2.59 & -2.71 & -3.93 & -6.34 & -7.99 \\ \text { U.S. } & 19 & 9 & 5.70 & 4.31 & 2.91 & 2.18 & -1.90 & -2.69 & -5.72 & -7.82 \\ \text { WORLD } & 19 & 6 & 5.28 & 5.23 & 2.72 & 2.01 & -2.14 & -2.76 & -4.88 & -8.51\end{array}$

Notes:

Total: total number of observations larger (in absolute value) than two standard deviations.

Single: number of extreme observations not followed nor preceded by another extreme observation in four weeks.

max l: largest observation.

max 2: second largest observation.

$\max 5 \%: 5 \%$ fractile of the largest observations.

$\max 10 \%: 10 \%$ fractile of the largest observations.

min 1: smallest observation.

$\min 2$ : second smallest observation.

$\min 5 \%: 5 \%$ fractile of the smallest observations.

min $10 \%: 10 \%$ fractile of the smallest observations. 
TABLE 3. CORRELATION MATRIX

A.- Levels

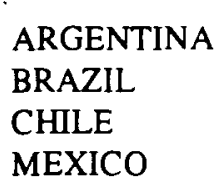

AUSTRALIA

CANADA

GERMANY

JAPAN

U.K.

U.S.

WORLD

B. - Squared Series

ARGENTINA

BRAZIL

CHILE

MEXICO

AUSTRALIA

CANADA

GERMANY

JAPAN

U.K.

U.S.

WORLD

\begin{tabular}{|c|c|c|c|c|c|c|c|c|c|}
\hline ARG BRA & $\mathrm{CHI}$ & MEX & AUS & CAN & GER & JAP & UK & US & WLD \\
\hline 1.000 .080 & .162 & .231 & .044 & .007 & -.085 & .042 & -.076 & .147 & .090 \\
\hline \multirow[t]{10}{*}{1.000} & .130 & .274 & .131 & .069 & .029 & -.020 & -.005 & -.004 & -.016 \\
\hline & 1.000 & .210 & .071 & .054 & .038 & .067 & -.014 & .007 & .037 \\
\hline & & 1.000 & .044 & .099 & .115 & .088 & -.001 & .104 & .100 \\
\hline & & & 1.000 & .348 & .250 & .256 & .261 & .245 & .369 \\
\hline & & & & 1.000 & .210 & .168 & .242 & .536 & .426 \\
\hline & & & & & 1.000 & .377 & .502 & .368 & .620 \\
\hline & & & & & & 1.000 & .374 & .299 & .799 \\
\hline & & & & & & & 1.000 & .351 & .617 \\
\hline & & & & & & & & 1.000 & .700 \\
\hline & & & & & & & & & 1.000 \\
\hline
\end{tabular}

\begin{tabular}{|c|c|c|c|c|c|c|c|c|c|}
\hline ARG BRA & $\mathrm{CHI}$ & MEX & AUS & CAN & GER & JAP & UK & US & WLD \\
\hline 1.000 .085 & .073 & -.003 & -.068 & .018 & .078 & .032 & .054 & -.007 & .094 \\
\hline \multirow[t]{10}{*}{1.000} & .091 & .068 & .007 & -.053 & .044 & .123 & -.052 & -.022 & -.022 \\
\hline & 1.000 & .047 & -.033 & -.029 & -.002 & .133 & -.022 & -.032 & .023 \\
\hline & & 1.000 & -.046 & -.051 & .005 & .172 & -.047 & .023 & .023 \\
\hline & & & 1.000 & .298 & .037 & .012 & .041 & .094 & .069 \\
\hline & & & & 1.000 & .018 & -.004 & .057 & .302 & .140 \\
\hline & & & & & 1.000 & .186 & .220 & .423 & .631 \\
\hline & & & & & & 1.000 & .138 & .183 & .514 \\
\hline & & & & & & & 1.000 & .201 & .387 \\
\hline & & & & & & & & 1.000 & .678 \\
\hline & & & & & & & & & 1.000 \\
\hline
\end{tabular}


TABLE 4. TAIL ESTIMATES

A. Full Sample

MARKET $\alpha+$

Lower Tail Exceedence Level $\left(x_{p}\right)$

$$
H_{11}: \alpha<2 p=1 / n \quad p=1 / 2 n \quad p=1 / 3 n
$$

I. Latin American Emerging Markets

\begin{tabular}{|c|c|c|c|c|c|c|c|}
\hline ARGEN & $\begin{array}{l}2.049 \\
(0.48) \\
\mathrm{m}=18\end{array}$ & $\begin{array}{c}1.989 \\
(0.35) \\
m=32\end{array}$ & $\begin{array}{c}2.522 \\
(0.58) \\
m=19\end{array}$ & 1.138 & -.467 & -.661 & -.811 \\
\hline BRAZIL & $\begin{array}{l}3.203 \\
(0.92) \\
m=12\end{array}$ & $\begin{array}{c}2.104 \\
(0.41) \\
m=26\end{array}$ & $\begin{array}{c}2.663 \\
(0.46) \\
m=33\end{array}$ & 1.904 & -.504 & -.701 & -.850 \\
\hline CHILE & $\begin{array}{l}2.373 \\
(0.44) \\
\mathrm{m}=29\end{array}$ & $\begin{array}{c}2.013 \\
(0.36) \\
\mathrm{m}=32\end{array}$ & $\begin{array}{c}2.513 \\
(0.30) \\
m=71\end{array}$ & 2.161 & -.189 & -.267 & -.327 \\
\hline MEXICO & $\begin{array}{l}3.990 \\
(1.03) \\
m=15\end{array}$ & $\begin{array}{c}1.789 \\
(0.28) \\
m=42\end{array}$ & $\begin{array}{c}2.489 * \\
(0.39) \\
m=41\end{array}$ & 1.566 & -.316 & -.466 & -.585 \\
\hline \multicolumn{8}{|c|}{ II. Industrial Markets } \\
\hline AUSTR & $\begin{array}{l}4.88 \\
(1.69) \\
m=7\end{array}$ & $\begin{array}{c}4.731 \\
(1.50) \\
m=10\end{array}$ & $\begin{array}{l}5.510 \\
(1.47) \\
m=14\end{array}$ & 6.566 & -.067 & -.078 & -.085 \\
\hline CANADA & $\begin{array}{l}4.149 \\
(1.25) \\
m=11\end{array}$ & $\begin{array}{c}3.353 \\
(0.54) \\
m=38\end{array}$ & $\begin{array}{c}3.466 \\
(0.71) \\
m=24\end{array}$ & 3.591 & -.059 & -.073 & -.082 \\
\hline GER & $\begin{array}{l}4.141 \\
(1.31) \\
m=10\end{array}$ & $\begin{array}{c}3.532 \\
(0.98) \\
m=13\end{array}$ & $\begin{array}{c}3.558 \\
(0.80) \\
\mathrm{m}=20\end{array}$ & 3.484 & -.081 & -.096 & -.106 \\
\hline JAPAN & $\begin{array}{l}3.125 \\
(0.76) \\
m=17\end{array}$ & $\begin{array}{l}3.740 \\
(1.13) \\
m=11\end{array}$ & $\begin{array}{l}3.111 \\
(1.81) \\
\mathrm{m}=22\end{array}$ & 2.606 & -.135 & -.168 & -.192 \\
\hline U.K. & $\begin{array}{l}3.651 \\
(0.91) \\
m=16\end{array}$ & $\begin{array}{l}4.985 \\
(1.50) \\
m=11\end{array}$ & $\begin{array}{l}4.404 \\
(0.85) \\
m=27\end{array}$ & 6.246 & -.070 & -.081 & -.087 \\
\hline U.S. & $\begin{array}{l}4.884 \\
(1.47) \\
m=11\end{array}$ & $\begin{array}{c}3.169 \\
(0.62) \\
m=26\end{array}$ & $\begin{array}{c}3.984 \\
(0.80) \\
m=25\end{array}$ & 4.960 & -.062 & -.077 & -.088 \\
\hline WORLD & $\begin{array}{l}2.887 \\
(0.58) \\
\mathrm{m}=25\end{array}$ & $\begin{array}{c}2.915 \\
(0.58) \\
m=25\end{array}$ & $\begin{array}{c}3.307 \\
(0.76) \\
m=19\end{array}$ & 2.848 & -.071 & -.091 & -.104 \\
\hline
\end{tabular}

Notes:

* Equality of lower tail and upper tail rejected at the $5 \%$ level. 
TABLE 5. Lower tail estimates for Different Portfolios

Proportion of

LA in port $\alpha$.

$.0 \% \quad 3.169$

$5 \% \quad 2.991$

$10 \% \quad 2.945$

$15 \% \quad 3.070$

$20 \% \quad 2.884$

$25 \% \quad 2.145$

$30 \% \quad 2.183$

$40 \% \quad 2.339$

$50 \% \quad 1.969$

$60 \% \quad 1.725$

$70 \% \quad 1.747$

$75 \% \quad 1.818$

$80 \% \quad 1.632$

$85 \% \quad 1.641$

$90 \% \quad 1.834$

$95 \% \quad 1.774$

$100 \% \quad 1.680$

$$
\mathrm{SE}(\alpha \cdot) \quad \mathrm{m}
$$

$0.622 \quad 26$

$0.556 \quad 29$

$0.676 \quad 19$

$0.704 \quad 19$

$0.721 \quad 16$

$0.405 \quad 28$

$0.476 \quad 21$

$0.585 \quad 16$

$0.464 \quad 18$

$0.396 \quad 19$

$0.276 \quad 40$

$0.291 \quad 39$

$0.385 \quad 18$

$0.398 \quad 17$

$0.315 \quad 34$

$0.292 \quad 37$

$0.269 \quad 39$
Exceedence Levels and Returns

$\begin{array}{llll}\mathrm{X}_{\mathrm{n}-\mathrm{m}} \delta=1 / \mathrm{n} & (\mathrm{R}-\mathrm{r}) /(\mathrm{r}-\mathrm{q}) \delta=1 / 2 \mathrm{n} & (\mathrm{R}-\mathrm{r}) /(\mathrm{r}-\mathrm{q}) \\ -0.022-.062 & .0146 & -.077 & .0118 \\ -0.020-.061 & .0166 & -.077 & .0133 \\ -0.022-.059 & .0188 & -.074 & .0149 \\ -0.022-.057 & .0211+ & -.072 & .0169+ \\ -0.024-.063 & .0201 & -.080 & .0166 \\ -0.018-.085 & .0167 & -.118 & .0121 \\ -0.022-.089 & .0171 & -.123 & .0124 \\ -0.030-.098 & .0177 & -.131 & .0132 \\ -0.031-.135 & .0144 & -.192 & .0101 \\ -0.033-.182 & .0118 & -.272 & .0079 \\ -0.025-.209 & .0113 & -.311 & .0076 \\ -0.028-.212 & .0116 & -.310 & .0079 \\ -0.044-.257 & .0100 & -.394 & .0065 \\ -0.048-.272 & .0098 & -.415 & .0064 \\ -0.037-.252 & .0110 & -.368 & .0075 \\ -0.037-.280 & .0103 & -.414 & .0069 \\ -0.036-.322 & .0093 & -.486 & .0061\end{array}$

Notes:

+ : preferred portfolio. 


\section{References}

Arzac, E.R. and V.S. Bawa (1977). "Portfolion Choice and Equilihrium in Capital Markets with SafetyFirst Investors," Journal of Financial Economics. 4. 277-288.

Baillie, R.T. and R.P. DeGennaro (1990), "Stuck Returns and Volatility." Journal of Financial and Quantitative Analysis, 25, 203-214.

Bekaert, G. and C.R. Harvey (1995). "Time-Varying World Market Integration." Journal of Finance, $50,403-444$.

Bekaert, G. and C.R. Harvey (1996). "Emerging Equity Market Volatility," Department of Finance, Duke University, manuscript.

Blattberg, R.C. and N.J. Gonedes (1974). "A Comparison of the Stable and Student Distribution as Statistical Models for Stock Prices," Journal of Business. 244-280.

Bollerslev, T.P. (1987), "A Conditional Time Series Model for Speculative Prices and Rates of Returns," Review of Economics and Statistics, 69, 524-54.

Cho, D.C, C.S. Eun and L.W. Senbet (1986). "International Arbitrage Pricing Theory: An Empirical Investigation," Journal of Finance, 41. 313-329.

Chuhan, P. (1992), "Sources of Portfolio Investment in Emerging Markets." manuscript.

Claessens, S., S. Dasgupta and J. Glen (1995). "Return Behavior in Emerging Stock Markets," World Bank Economic Review, 9, 131-151.

De Santis, G. (1993), "Asset Pricing and Portfolio Diversification: Evidence from Emerging Financial Markets," Department of Finance and Business Economics. University of Southern California, unpublished manuscript.

De Santis, G. and S. Imrohoroglu (1995). "Stock Returns and Volatility in Emerging Financial Markets," Department of Finance and Business Economics, University of Southern California, unpublished manuscript.

Engle. R.F. and R. Susmel (1993). "Common Volatility in International Equity Markets," Journal of Business and Economic Statistics. 11.2, 167-176

Fama, E. (1965), "The Behavior of Stock Market Prices." Journal of Business, 38, 34-105.

Goldie C.M. and R.L. Smith. "Slow Variation with Remainder: Theory and Applications," Quarterly Journal of Mathematics, 38, 45-71.

Hall, P. (1990). "Using the Bootstrap to Estimate Mean Squared Error and Select Smoothing Parameter in Nonparametric Problems." Journal of Multivariate Analysis, 177-203. 
Hargis, K. (1994), "Time-Varying Transmission of Prices and Volatility Latin American Equity Markets 1988-1994." Department of Economics. University of Illinois at Urbana-Champaign. unpublished manuscript.

Harvey, C.R. (1993), "Portfolio Enhancement with Emerging Markets and Conditioning Information," in S. Claessens and S. Gooptu (eds.): Portfolio Investment in Developing Countries, World Bank, Washington, D.C.

Harvey, C.R. (1994), "Conditional Asset Allocation in Emerging Markets," Department of Finance, Duke University, manuscript.

Harvey, C.R. (1995a), "Predictable Risk and Returns in Emerging Markets," Review of Financial Studies, 8, 773-816.

Harvey, C.R. (1995b), "The Risk Exposure of Emerging Equity Markets," World Bank Economic Review, 9, 19-50.

Hill, B.M. (1975) " A Simple General Approach to Inference About the Tail of a Distribution," The Annals of Statistics, 3, 1163-1173.

Hols, M. and C.G. de Vries (1991), "The Limiting Distribution of Extremal Exchange Rate Returns," Journal of Applied Econometrics. 287-302.

Jansen, D.W.and C.G. de Vries (1991), "On the Frequency of Large Stock Returns: Putting Booms and Busts into Perspective," The Review of Economics and Statistics, 18-24.

Jansen, D.W., K.G. Koedijk, and C.G. de Vries (1996). "Operationalizing Safety First Portfolio Selection using Extreme Value Theory," Department of Economics, Texas A\&M University, manuscript.

Koedijk, K.G, M.M.A. Schafgans and C.G de Vries (1990). "The Tail Index of Exchange Rate Returns," Journal of International Economics. 29. 93-108.

Leadbetter, M.R., G. Lindgren and H. Rootzen (1983). Extreme and Related Properties of Random Sequences and Processes. Berlin. Germany: Springer-Verlag.

Longin, F. (1993), "Booms and Crashes: Applicarion of Extreme Value Theory to the U.S. Stock Market," London Business School. manuscript.

Loretan, M. and P.C.B. Phillips (1994). "Testing the Covariance Stationarity of Heavy-Tailed Time Series: An Overview of the Theory With Applications to Several Financial Datasets." Journal of Empirical Finance, 1, 211-248.

Mandelbrot. B.B. (1963), "The Variation of Certain Speculative Prices." Journal of Business, 36, 394419.

McFarland. J.W.. R.R. Pettit, and S.K. Sung (1982). "The Distribution of Foreign Exchange Price 
Changes: Trading Day Effects and Risk Measurement." Jorunal of Finance. 38. 693-715.

Roy, A.D. (1952), "Safety First and the Holding of Assets," Econometrica. 431-449.

Tesar, L. and I.M. Werner (1994), "International Securities Transaction and U.S. Portfolio Choice," in The Internationalization of Equity Markets. Chicago. Ill. : The University of Chicago Press.

Tesar, L. and I.M. Werner (1995), "U.S. Equity Investment in Emerging Stock Markets," World Bank Economic Review, 9, 109-29. 


\section{FUNDAÇÃo GETULIO VARGAS \\ BIBLIOTECA}

ESTE VOLUME DEVE SER DEVOLVIDO À BIBLIOTECA NA ÚLTIMA DATA MARCADA

\begin{tabular}{l|l|l|l}
\hline 10 JUI & $0006 /$ & & \\
\hline & & & \\
\hline & & & \\
\hline & & & \\
\hline & & & \\
\hline & & & \\
\hline & & & \\
\hline & & & \\
\hline & & & \\
\hline & & & \\
\hline & & & \\
\hline & & & \\
\hline & & & \\
\hline
\end{tabular}

N.Cham. P/EPGE SPE S964ex

Autor: Susmel, Raul.

Titulo: Extreme observations and diversification in Latin

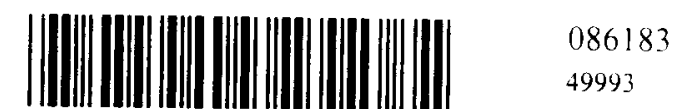

FGV - BMHS

N'P Pat. .F84/98 